\title{
Topographic Restriction of TAG-1 Expression in the Developing Retinotectal Pathway and Target Dependent Reexpression during Axon Regeneration
}

\author{
Dirk M. Lang, ${ }^{*}$ J ames T. Warren J r., ${ }^{\dagger}$ Christiane Klisa, ${ }^{\ddagger}$ \\ and Claudia A. O. Stuermer*,1 \\ *Department of Biology, University of Konstanz, Universitätsstrasse 10, 78467 Konstanz, \\ Germany; ${ }^{\dagger}$ Penn State Erie, The Behrend College, School of Science, Erie, Pennsylvania \\ 16563-0203; and ${ }^{\ddagger}$ Max-Planck-Institute for Molecular Cell Biology and Genetics \\ (Dresden), c/o Institute of Neurobiology, University of Heidelberg, \\ Im Neuenheimer Feld 364, 69120 Heidelberg, Germany
}

TAG-1, a glycosylphosphatidyl inositol (GPI)-anchored protein of the immunoglobulin $(\mathrm{Ig})$ superfamily, exhibits an unusual spatiotemporal expression pattern in the fish visual pathway. Using in situ hybridization and new antibodies (Abs) against fish TAG-1 we show that TAG-1 mRNA and anti-TAG-1 staining is restricted to nasal retinal ganglion cells (RGCs) in 24- to 72-h-old zebrafish embryos and in the adult, continuously growing goldfish retina. Anti-TAG-1 Abs selectively label nasal RGC axons in the nerve, optic tract, and tectum. Axotomized RGCs reexpress TAG-1, which occurs as late as $\mathbf{1 2}$ days after optic nerve lesion, when regenerating RGC axons arrive in the tectum, suggesting TAG-1 reexpression is target contactdependent. Accordingly, TAG-1 reexpression ceases upon interruption of the regenerating projection by a second lesion. The topographic restriction of TAG-1 expression and its target dependency during regeneration suggests that TAG-1 might play a role in the retinotopic organization and restoration of the retinotectal pathway.

\section{INTRODUCTION}

Developing neurons express a complex array of cell surface molecules, which enable the growth cone to perceive cues in its environment and to steer along predetermined pathway to its target. Among the many cell surface recognition molecules on growing axons are

\footnotetext{
${ }^{1}$ To whom correspondence and reprint requests should be addressed. Fax: 49/7531-883894. E-mail: claudia.stuermer@uni-konstanz.de.
}

the cell adhesion molecules (CAMs) of the immunoglobulin superfamily (IgSF) with various forms and a range of functions (Brümmendorf and Rathjen, 1995).

Long axons such as those of commissural neurons in the spinal cord or retinal ganglion cells (RGCs) in the visual system, which cover long distances and cross several decisional regions to reach their targets, express several different IgSF CAMs. These CAMs often promote growth cone elongation and axon fasciculation, but it appears that they also act as sensors or receptors for guidance cues in regions where growth cones make pathway decisions (Stoeckli and Landmesser, 1995, 1998; Stoeckli et al., 1997; Ott et al., 1998; Leppert et al., 1999; Fitzli et al., 2000). Such has recently been discovered for the GPI-anchored IgSF CAM TAG-1/axonin-1, which consists of six Ig loops and four fibronectin type III (FN) domains and which, together with $\mathrm{L} 1 / \mathrm{Ng}$ CAM, NrCAM, and F3/F11 belongs to the Ig/FN III subfamily (Furley et al., 1990; Stoeckli et al., 1997; Fitzli et al., 2000).

TAG-1/axonin-1 promotes growth cone elongation and contributes to fasciculation by homophilic (trans) interactions with the same molecules on opposed membranes and by heterophilic cis interactions with $\mathrm{Ng}$ CAM/L1 in the same membrane (Furley et al., 1990; Kuhn et al., 1991; Rader et al., 1993; Felsenfeld et al., 1994). Furthermore, it interacts with NrCAM. This interaction is of crucial importance during pathfinding of commissural axons in the chick where axonin-1 on commissural growth cones functions in the recognition of 
floor plate-associated $\mathrm{NrCAM}$, and thus in guidance of commissural growth cone across the floor plate.

TAG-1/axonin-1 is also expressed by developing RGC axons in the visual system of mammals and birds (Wolfer et al., 1994; Halfter et al., 1994; Jung et al., 1997) and was more recently found to be present in the retina of zebrafish embryos (Warren et al., 1999).

In the present study, we examined the spatiotemporal expression of TAG-1 in the fish visual pathway to determine its distribution and potential involvement in axon growth. In the course of these investigations we discovered an unexpected topographically restricted expression of TAG-1 in the developing fish retinotectal system and a delayed onset of TAG-1 reexpression after optic nerve lesion. Zebrafish embryos were analyzed to explore TAG-1 expression during development of the retina-to-tectum projection, which forms between 28 and $72 \mathrm{hpf}$ and results in the establishment of a retinotopically organized map formed by RGC axons in the tectal neuropil (Stuermer, 1988a). Here, we find TAG-1 mRNA specifically in RGCs of the nasal retina and TAG-1 protein on nasal axons. This restricted expression was also observed during the continuous growth in adult fish which occurs by the addition of new RGCs around the retinal margin (Johns, 1977). Growth of axons from new RGCs is accompanied by a regulated expression of IgSF proteins such as NCAM (Bastmeyer et al., 1990), neurolin (Paschke et al., 1992), the homolog of SC-1/DM-GRASP/BEN (Tanaka et al., 1991; Burns et al., 1991; Pourquie et al., 1992), and the L1-related E587 antigen (Vielmetter et al., 1991; Giordano et al., 1997). With antibodies against TAG-1, we observe bright staining on axons of mRNA-expressing nasal RGCs and weak staining over the remaining retina.

We also wanted to know if RGCs reexpress TAG-1 during axon regeneration, since earlier findings showed that axotomized RGCs in adult rats downregulate TAG-1 expression and fail to upregulate it even when they regenerate an axon (Jung et al., 1997). Axotomized RGCs in fish reexpress the IgSF CAMs mentioned and provide them to regrowing axons along their path into the optic tectum (Stuermer and Leppert, 2000). Our experiments reveal that axotomized RGCs reexpress TAG-1. This reexpression occurs in an unusual time course compared to the other IgSF CAMs and in correlation with target contact reformation (Stuermer and Easter, 1984a). Furthermore, RGCs which reexpress TAG-1 are unevenly distributed over the retina. Most are localized in the nasal half and fewer in the temporal half. The late onset of TAG-1 reexpression, its dependence on target contact, and preferential expression in nasal RGC axons could indicate that TAG- 1 in fish perhaps participates in the selective fasciculation of nasal axons and in map (re-)formation.

\section{RESULTS}

\section{Position-Dependent Expression of TAG-1 in the Retinotectal Pathway}

Embryo. In zebrafish embryos, the very first RGCs differentiate in a ventronasal cluster close to the optic fissure at $28 \mathrm{hpf}$ and are identified by their expression of neurolin mRNA (Laessing and Stuermer, 1996). These first RGCs were also found to express TAG-1 mRNA (Fig. 1a). The cells and their axons, which extend at $32 \mathrm{hpf}$, are recognized by anti-TAG-1 and by anti-neurolin Abs (Figs. 1b and 1c). Around 40-48 hpf when axons from both nasal and temporal retina course toward the tectum (Stuermer, 1988a), a subpopulation of the TAG-1 positive axons are also labeled by antineurolin $\mathrm{mAb}$. It is apparent at $72 \mathrm{hpf}$ that these axons are derived from nasal RGCs. In situ hybridizations with the TAG- 1 probe at $72 \mathrm{hpf}$ reveal that only RGCs of the nasal retina express TAG-1 mRNA (Fig. 1d). Accordingly, the nasal axons are brightly labeled by anti-TAG-1 Abs (Fig. 1e). TAG-1 mRNA was not detected in temporal RGCs but the axons from the temporal retina were weakly labeled, probably due to the presence of soluble TAG-1 in the vitreous (see below). In contrast, with anti-E587 mAb labeling is equally intense in axons from the temporal and nasal retina (Fig. 1f). The RGC axons establish a retinotopically organized projection at $72 \mathrm{hpf}$ (Stuermer, 1988a) and TAG1-labeled axons in embryos of this age arborize in the caudal aspect of the tectal neuropil (Fig. 1g). These results establish TAG-1 as a positional marker of nasal RGCs and RGC axons.

Adult fish. The restriction of TAG-1 mRNA expression to nasal RGCs was also observed in the adult retina of both zebrafish and goldfish and is confined to the new RGCs (Figs. 2 and 3), which are continuously generated around the margin of the retina (Johns, 1977). The new RGCs, which extend their axons in radial routes toward the optic disk at the center of the retina, are recognized by $\mathrm{mAbs}$ against the growth-associated proteins E587 antigen (Bastmeyer et al., 1995) (Fig. 2). Whereas anti-E587 mAb labels growing axons from all new RGCs with equal intensity, the anti-TAG-1 Abs produce bright staining of the nasal RGC axons (Fig. 2) and weak staining in the rest of the retina. The brighter TAG-1 positive axons of the nasal retina derive from new RGCs at the margin which exhibit TAG-1 on the 

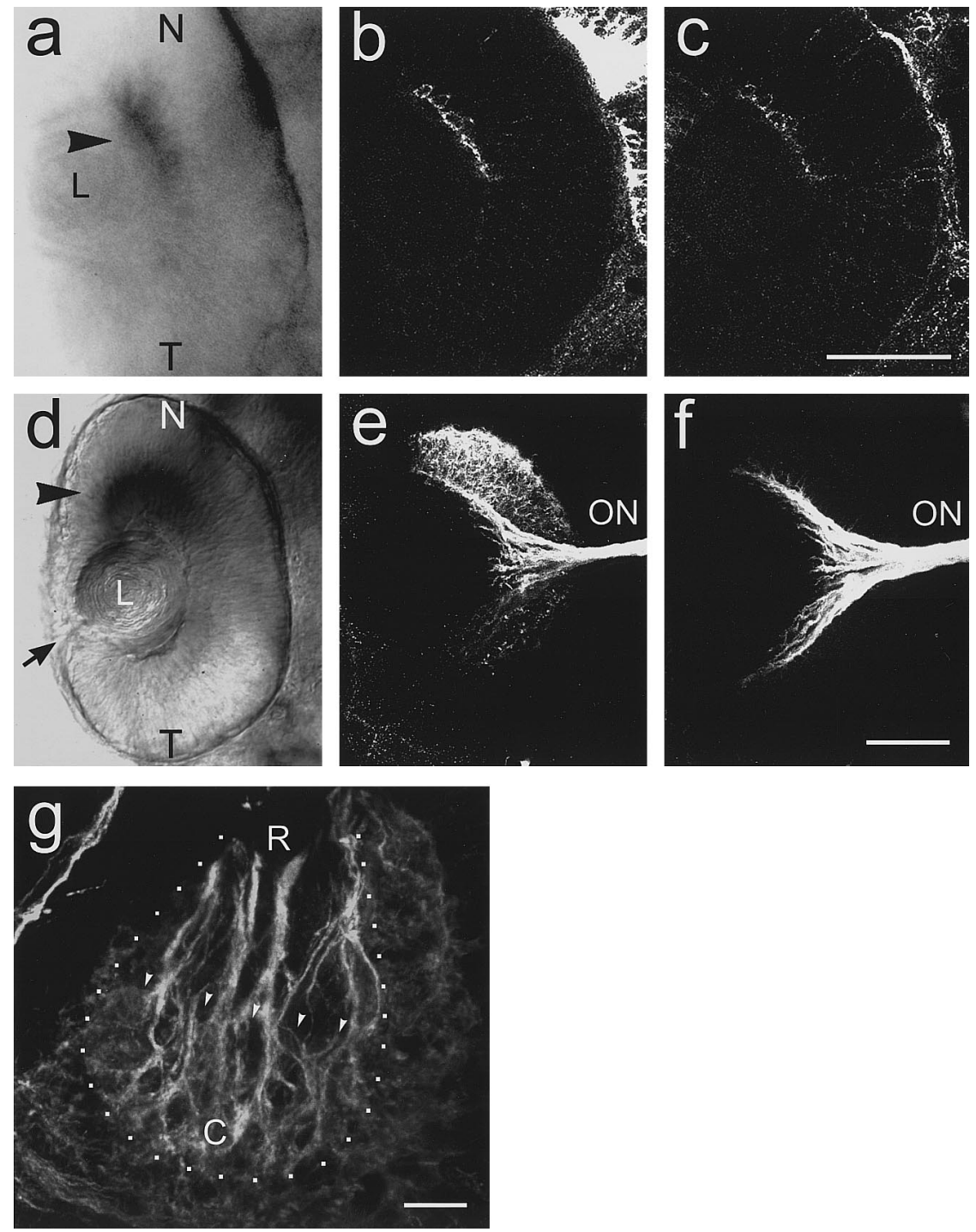

FIG. 1. TAG-1 expression pattern in the retinotectal pathway of zebrafish embryos. Dorsal view on the head of embryos. N, nasal; T, temporal retina. The arrow in (d) points to the optic fissure. L, lens; ON, optic nerve. (a) In situ hybridizations reveal TAG-1 mRNA in a small group of RGCs in the nasal retina (arrowhead) of a 28-hpf embryo. (b, c) The differentiating RGCs exhibit surface labeling with anti-TAG-1 Abs (b) and with anti-neurolin mAb (c). Scale bar, $200 \mu \mathrm{m}$. (d) In the 72-hpf embryo, TAG-1 mRNA-expressing RGCs are confined to the nasal retina (arrowhead). (e) Anti-TAG-1 Abs label the RGCs of the nasal retina and brightly stain the nasal RGC axons in the retina and optic nerve. (f) Anti-E587 mAb label both the temporal and nasal axons in the retina and optic nerve. (g) Anti-TAG-1 Abs label the RGC axons in the neuropil of the developing optic tectum (72 hpf). The path is typical of nasal axons which pass through the rostral tectum and branch in the caudal aspect (arrowheads) of the neuropil (delineated by dots). R, rostral; C, caudal. Scale bar, $10 \mu \mathrm{m}$.

surface of their somata (Figs. 3a and 3b). TAG-1 mRNA was not detectable in the peripheral RGCs of the temporal retina (Figs. 3c and 3d) and no anti-TAG-1 staining was observed on the surface of the temporal RGCs nor was there a comparably bright staining of young temporal RGC axons. Young axons are, however, labeled by anti-E587 $\mathrm{mAb}$ in the nasal and temporal retina (Figs. 3e and 3f). The weaker anti-TAG-1 staining of temporal axons most likely results from the presence of soluble TAG-1 in the vitreous (Fig. 4), which may bind to TAG-1 binding molecules on retinal cells. The staining of cellular processes of unknown identity, observed in both the nasal and temporal retina (Figs. 3b and $3 \mathrm{~d}$ ), may also result from soluble TAG-1 and its heterophilic binding, since there are no TAG-1 mRNAexpressing cells other than nasal RGCs at the retinal 


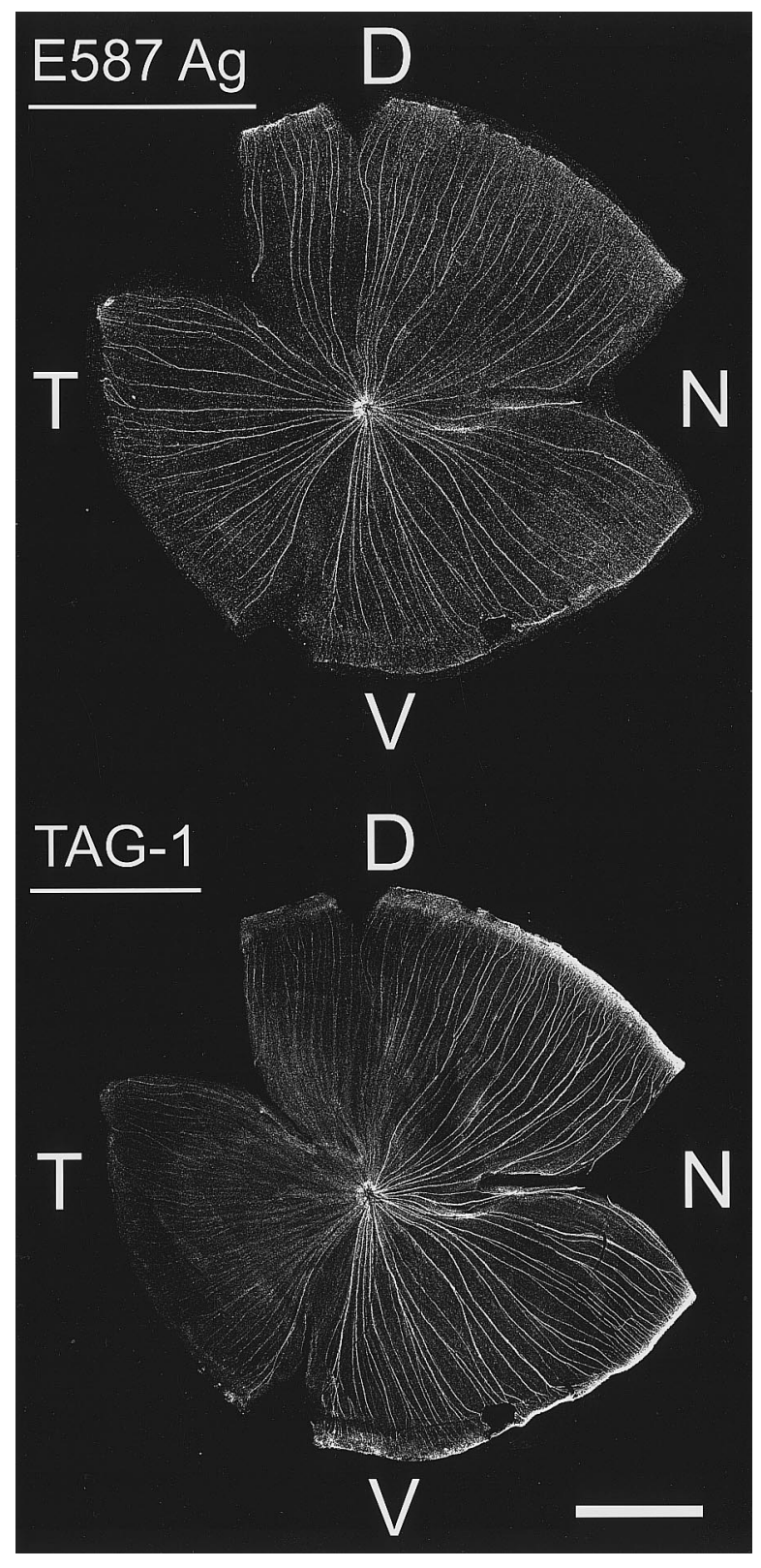

FIG. 2. Asymmetric staining with anti-TAG Abs of young RGC axons in the adult goldfish retina. Retina wholemount, double labeled by anti-E587 and anti-TAG-1 Abs. Anti-E587 Abs brightly label all young RGC axons on their path from new RGCs at the retinal margin to the optic disk in the center. Anti-TAG-1 Abs label brightly the young RGC axons of the nasal retina $(\mathrm{N})$ and weakly the axons of the temporal retina $(\mathrm{T})$. Scale bar, $1 \mathrm{~mm}$.

periphery (Figs. 3a and 3b). To test whether the bright staining on the nasal RGCs and RGC axons is indicative of GPI-anchored TAG-1, freshly isolated, and unfixed retinae were exposed to PI-PLC, the enzyme that cleaves the GPI anchor. This treatment abolished almost completely TAG-1 immunoreactivity on young nasal RGCs and axons but did not abolish TAG-1 staining of the cellular processes nor the weak overall immunoreactivity in the retina (Figs. 5a and 5c). Moreover, PI-PLC did not affect the staining of axons with $\mathrm{mAb}$ against E587 antigen, which is a transmembrane protein (Figs. $5 \mathrm{~b}$ and $5 \mathrm{~d})$.

To determine if TAG- 1 is confined to a subpopulation of young axons during their growth into the tectum, wholemounts, and sections of the goldfish optic nerve, optic tract, and tectum were exposed to TAG-1 Abs. In the nerve, where young growing RGC axons are recognized by anti-neurolin and anti-E587 Abs (Fig. 6b), antiTAG-1 Abs labeled a subpopulation of the E587-positive axons (Figs. 6a and 6b). Since only RGCs of the nasal retina and their intraretinal axons are TAG-1 positive, the TAG-1-positive axons in the optic nerve are most likely nasal axons.

While approaching the tectum, young RGCs axons occupy a superficial position in the tract (Scholes, 1979; Vielmetter et al., 1991). Axons derived from the very temporal retina course directly into the very rostral tectum (Fig. 6c). The remaining young axons-separated according to their ventral and dorsal retinal origin (Stuermer and Easter, 1984a) - travel in two fascicles around the dorsomedial and ventrolateral tectal margin. Axons exit from these peripheral fascicles sequentially according to their retinal positional origin and their retinotopic destination in the tectum (Stuermer and Easter, 1984b; Easter and Stuermer, 1984; Stuermer, 1984). Nasal axons follow these peripheral pathways into caudal tectum. A dorsal view on the midtectal to caudal extent of the peripheral fascicle at the dorsomedial tectal margin shows that the axons are TAG-1 positive (Fig. 7a). A cross-section of this peripheral region of tectum also shows that TAG-1-labeled axons are confined to the peripheral-most fascicle (Fig. 7c).

This restricted expression of TAG-1 mRNA to new nasal RGCs and the appearance of GPI-linked TAG-1 on the young nasal RGC axons indicates that TAG-1 is a positional marker molecule, which may be relevant for the guidance of nasal RGC axons along the path toward their retinotopic target sites in the tectum.

\section{Reexpression of TAG-1 after Optic Nerve Lesion}

Optic nerve transection induces reexpression of the IgSF proteins E587 antigen and neurolin in all RGCs. This leads to the appearance of the proteins on all regenerating axons along their entire path into the tectum (Vielmetter et al., 1991; Paschke et al., 1992; Ankerhold et al., 1998; Ankerhold and Stuermer, 1999). The 

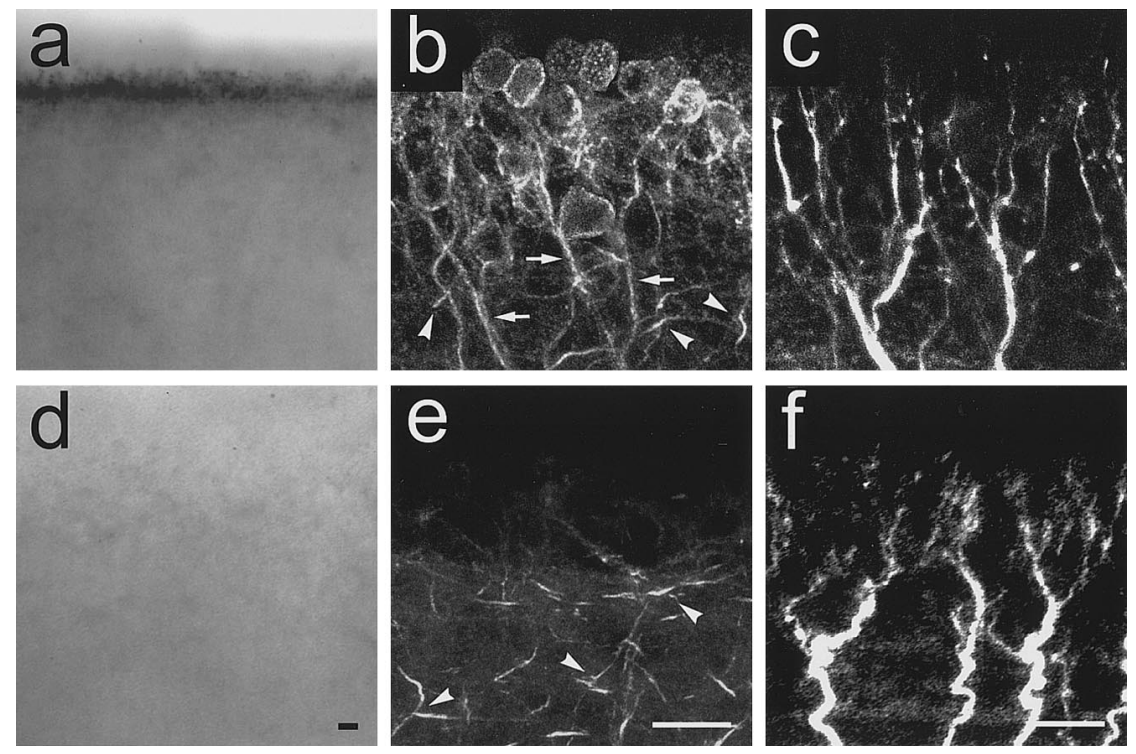

FIG. 3. Comparison of TAG-1 expression between the nasal and temporal retina. (a, d) TAG-1 mRNA is detected in new RGCs at the nasal aspect of the retinal margin (a), but not in RGCs of the temporal retina (d). (b, e) The new nasal RGCs exhibit anti-TAG-1 staining on their surface and on their axons (arrows) (b), whereas their counterparts on the temporal side remain unlabeled (e). On both sides, anti-TAG-1 Abs recognize cellular processes of unknown identity (arrowheads) and in the absence of TAG-1 mRNA (a, d). (c, f) Anti-E587 mAb stains both the young nasal (c) and temporal (f) axons. Scale bar, $20 \mu \mathrm{m}$.

first regenerating axons arrive in the rostral tectum between 10 and 12 days after lesion and establish synaptic connections (often in retinotopically incorrect regions), with tectal neurons soon after their arrival (Stuermer and Easter, 1984a). The tectum is invaded by regenerating axons at around 4 weeks after lesion, but it takes several weeks for the retinotopic projection to establish its near-normal order (Stuermer, 1988b,c; Schmidt et al., 1988).

TAG-1 reexpression in the retina. TAG-1 reexpression by axotomized RGCs occurred in an unusual spatiotemporal pattern. Whereas E587 mRNA was upregulated in many or most RGCs as early as 6 days after lesion (Ankerhold et al., 1998; Ankerhold and Stuermer, 1999) and continued to be expressed for weeks (Fig. 8a), TAG-1 mRNA was not observed at 2, 6, and 10 days after lesion (Fig. 8b). TAG-1 mRNA and protein were first detected in axon-regenerating RGCs around 12 days after lesion and thus in correlation with the arrival of axons in the tectum. Reexpression was always confined to a subpopulation of cells. The number of RGCs reexpressing TAG-1, reached a maximum between 21 and 30 days after lesion (Fig. 8c) and declined gradually over the next weeks. At all time points examined, the TAG-1 mRNA-expressing RGCs were located in the nasal retinal half and a few occurred in the temporal retina (Figs. $8 \mathrm{c}$ and $8 \mathrm{~d}$ ).

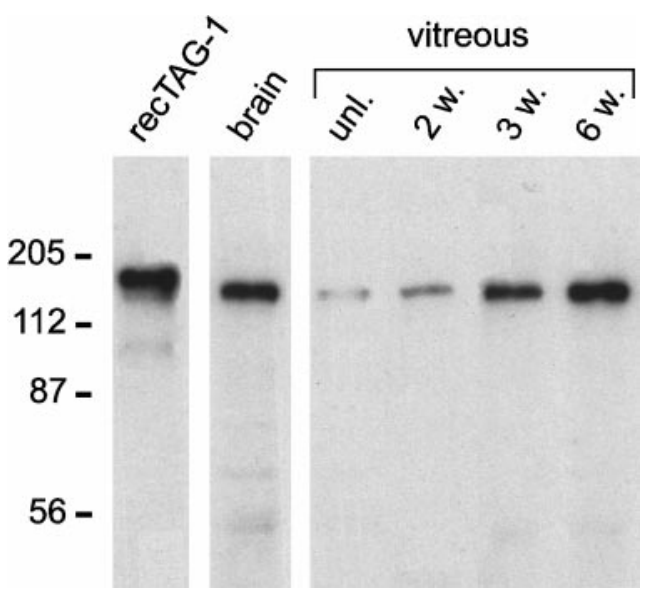

FIG. 4. Western blots with anti-TAG-1 Abs and recombinant TAG-1, with proteins from brain and vitreous. Lane 1: anti-TAG-1 Abs recognize recombinant TAG-1 protein produced by $\mathrm{CHO}$ cells, which exhibits a slightly higher apparent molecular weight than native TAG-1, probably due to its polyhistidine tail. Lane 2: anti-TAG-1 Abs recognize TAG-1 from goldfish brain with an apparent molecular weight of ca. $140 \mathrm{kDa}$. Lanes 3-6: anti-TAG-1 Abs recognize TAG-1 in the vitreous of goldfish eyes with unlesioned optic nerve (unl), and at 2,3 , and 6 weeks (w.) following optic nerve lesion. The gels were loaded with equal concentrations of proteins. The increasing intensity of the bands suggests an increase of soluble TAG-1 in the vitreous with time after lesion. Molecular weight markers are indicated to the left. 

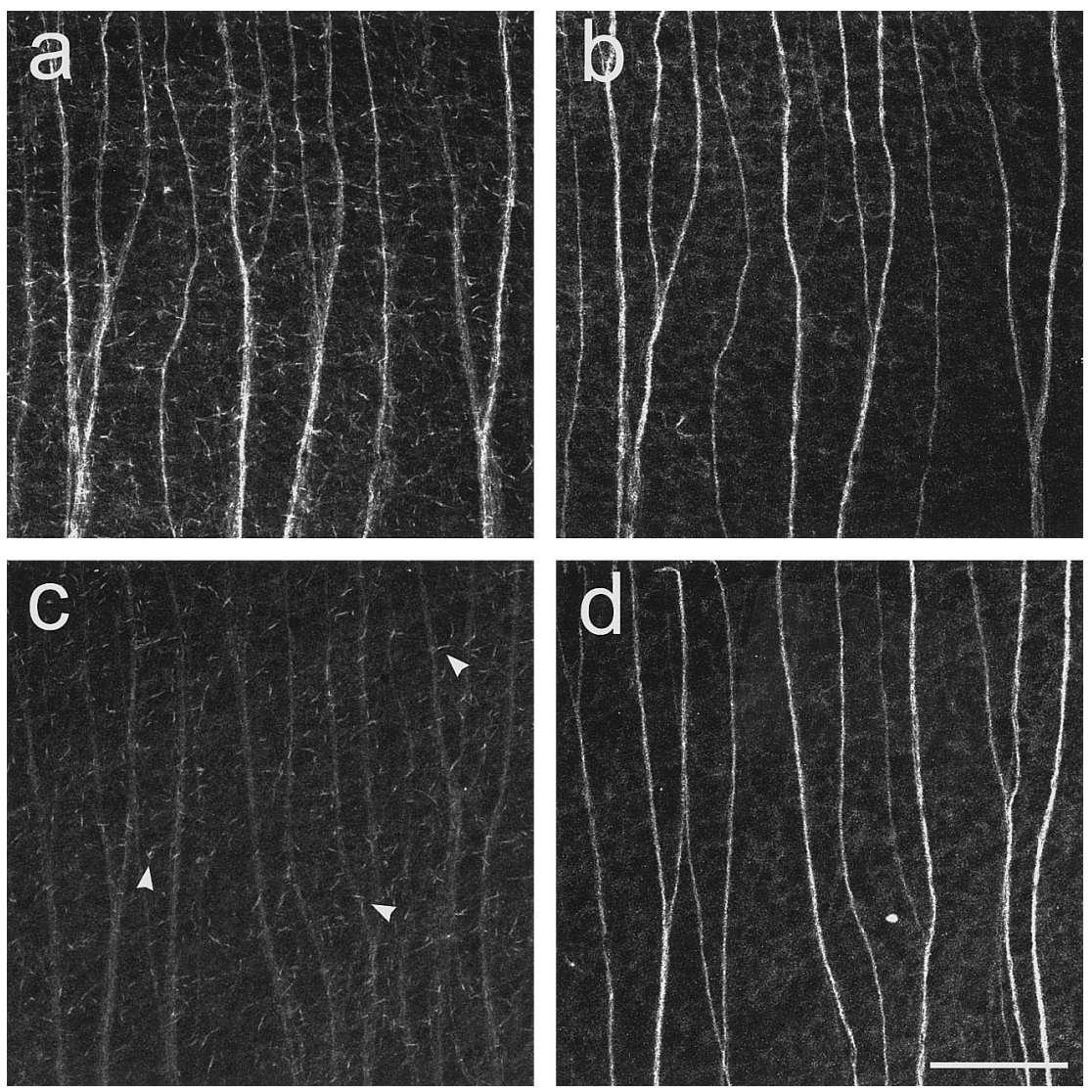

FIG. 5. PI-PLC treatment removes TAG-1 from young RGC axons. (a, b) When freshly excised and unfixed retina wholemounts are exposed to anti-TAG-1 (a) and E587 Abs (b), young growing axons on the nasal side are labeled. Labeling of cellular processes by anti-TAG-1 is also apparent (a). (c, d) Exposure of the unfixed retina to PI-PLC leads to a marked reduction of anti-TAG-1 Abs staining on the axons (c), whereas staining of cellular processes is unaffected by the treatment. Likewise, axonal staining with anti-E587 Abs remains intense (d). Scale bar, $100 \mu \mathrm{m}$.

Labeling of retinae with anti-TAG-1 Abs at 21 and 30 days after lesion shows a similar distribution: most TAG-1-positive RGCs are in the nasal retina and only few in the temporal retina (Figs. 8e and 8f). However, in contrast to developing neurons, the TAG-1-positive axotomized RGCs exhibit a granular, intracellular stain rather than surface staining (Fig. 8e'). Moreover, the intraretinal portions of axons of these RGCs do not exhibit the bright staining (Figs. 8e and 8e') seen on the young growing axons from the new RGCs at the margin of the nasal retina. Except for the young axons, all other axons showed a diffuse, weak labeling. This suggests that RGCs which reexpress TAG-1 retain a significant amount of protein in intracellular compartments, probably for transport of the protein to more distal regrowing portions of the axons outside the retina (Vogt et al., 1996). In parallel with TAG-1 reexpression by RGCs, the amount of TAG-1 in the vitreous increased, as is indi- cated by the intensity of the TAG-1 band in Western blots with proteins derived from the vitreous (Fig. 4).

TAG-1 reexpression in the optic nerve, tract, and tectum. In the optic nerve, where regenerating axons are abundant 21 days after lesion, TAG-1-positive axons were found throughout the nerve's cross sectional area (Fig. 9a). In nerve/tract wholemounts they are seen as a subpopulation of axons labeled by antineurolin mAb (Figs. 9d and 9e). Many regenerating axons in the nerve are neurolin-positive by 10 days after lesion (Fig. 9b), but they are not labeled at this stage by anti-TAG-1 Abs. This is consistent with the late onset of TAG-1 reexpression in the axotomized RGCs. The few fascicles that are TAG-1-positive are most likely the young axons from new RGCs at the retinal margin and these also occur in the unlesioned nerve (Fig. 9c). Since most RGCs which reexpress TAG-1 are in the nasal retina, most of the TAG-1-labeled axons in the nerve/tract and tectum 

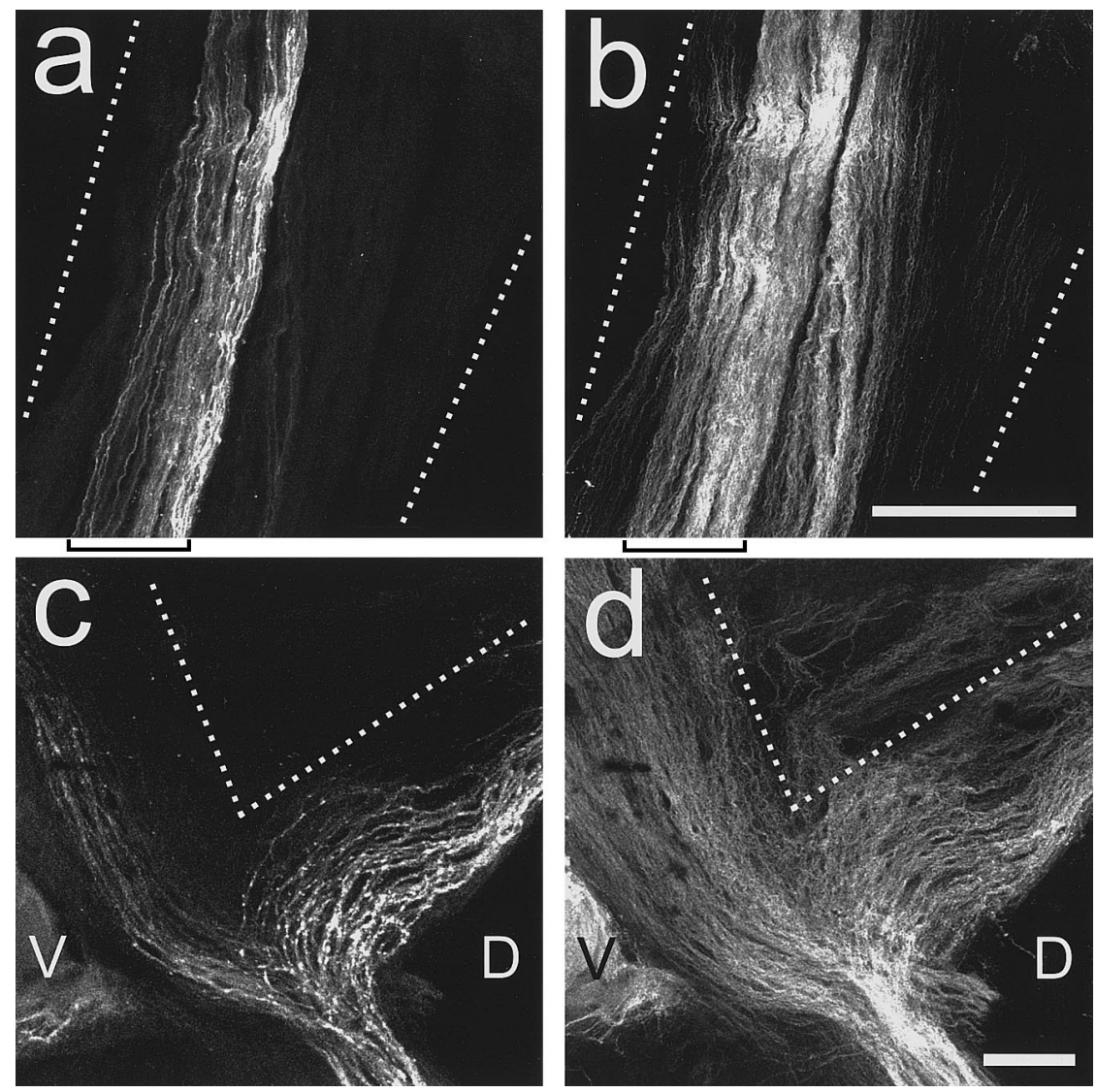

FIG. 6. TAG-1 staining of RGC axons in the optic nerve and tectum. Staining of RGC axons in nerve/tectum wholemounts. (a, b) Young growing RGC axons represent a subpopulation of all axons in the optic nerve, whose width is indicated by the dotted lines. Anti-E587 Abs recognize all young RGC axons (b), whereas anti-TAG-1 Abs (a) label a subpopulation of those seen in (b). (c, d) A dorsal view on the rostral aspect of the tectum and the incoming optic tract shows the young RGC axons in their path from the tract into rostral tectum (temporal RGC axons) and around the ventrolateral and dorsomedial tectal margins. (d) Anti-E587 Abs label all RGC axons, which are restricted to the more peripheral tectal aspects (dashed lines), but also labels tectal efferents in deeper layer visible in more central tectal regions. (c) With anti-TAG-1 Abs, a subpopulation of axons labeled by E587 Abs is stained, and their path along the dorsomedial and ventrolateral tectal margin is characteristic of nasal axons. Scale bars, $200 \mu \mathrm{m}$.

probably derive from nasal RGCs. That TAG-1-labeled axons are widely distributed over the nerve and tract is compatible with the notion that regenerating axons course in abnormal routes and fail to reestablish their normal neighborhood relations (Stuermer and Easter, 1984a; Stuermer, 1988b,c).

In the tectum, TAG-1-positive axons were found in all fascicles (the more rostrocentral and peripheral ones) (Fig. $7 \mathrm{~b}$ ), which is consistent with the fact that regenerating RGC axons travel aberrantly through the fascicles independent of their retinal positional origin and retinotopic tectal destination (Stuermer and Easter, 1984a; Stuermer, 1988b,c). Axons in the synaptic layers (SFGS, Stratum fibrosum et griseum superficiale) of the tectum, which is subjacent to the Stratum opticum (SO), are also labeled (Fig. 7d).
These results show a late onset of TAG-1 reexpression in axon-regenerating RGCs in temporal correlation with the reformation of target contact. TAG-1 reexpressing RGCs are significantly more abundant in the nasal compared to the temporal retinal half. Furthermore, while axons from RGCs reexpressing TAG-1 at 12 days or more after lesion show hardly any labeling in the intraretinal portion of their path, they are brightly labeled in the optic nerve, optic tract, and tectum. This staining appears from 12 days after lesion onwards and is not seen earlier although the nerve and tract contain already many regenerating axons at 8 and 10 days (Ankerhold et al., 1998). This and the finding that RGCs contain TAG-1 intracellularly, suggests that TAG-1 is transported within the axons and becomes visible only in the actively regrowing segment (Vogt et al., 1996) of 

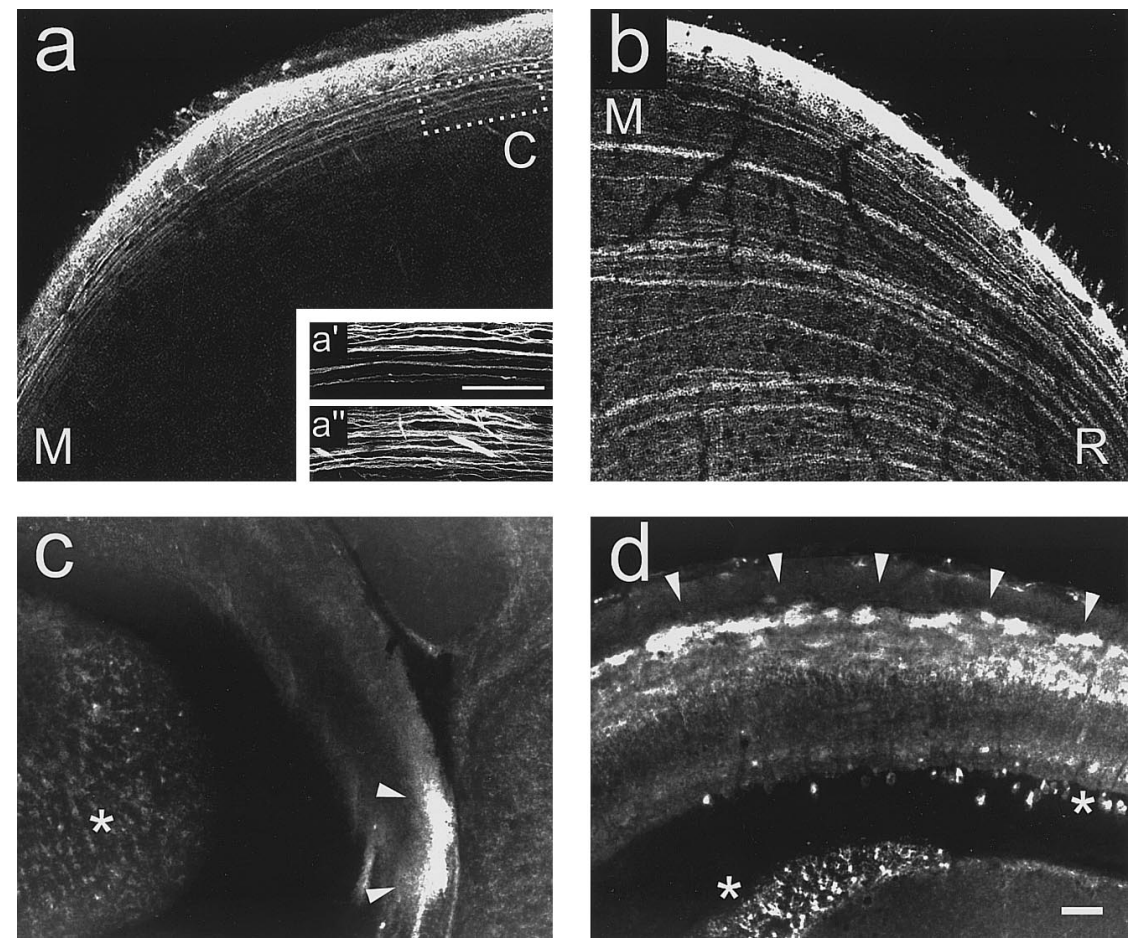

FIG. 7. The intratectal path of TAG-1 positive normal and regenerating RGC axons. (a, b) Dorsal view, tectal wholemounts; (c, d) longitudinal sections through tectum. (a) Young axons travel along the margin of the tectum (here dorsomedial). Anti-TAG-1-labeled axons can be followed from midtectal $(\mathrm{M})$ into the caudal tectum (C), and this path is typical of nasal RGC axons. Insert, at midtectal levels, TAG-1-expressing axons (a') represents a subpopulation of E587 antigen expressing axons (a"). Scale bar a', $50 \mu \mathrm{m}$. (b) Anti-TAG-1 labeled regenerating RGC axons, 4 weeks after optic nerve transection, are distributed over all fascicle pathways, along the peripheral margin and through more central fascicles. (c) A section through the tectum after exposure to anti-TAG-1 Abs, reveals the young labeled axons in the peripheral tectal fascicle (arrowheads). (d) Regenerating RGC axons at 4 weeks after optic nerve lesion are detected by anti-TAG-1 Abs in fascicles (arrowheads) and the subjacent layers where axons arborize and synapse. Anti-TAG-1 also labels cells and processes in deeper layers of the tectum (asterisk) and in other brain areas. Scale bars, $100 \mu \mathrm{m}$.

the regenerating axons. This unusual expression pattern suggests the following scenario: regenerating RGC axons, which contact the target, deliver a signal to their parent RGCs, which induces reexpression of TAG-1, whereupon the RGCs transport the protein to the regrowing portion of the axon (Vogt et al., 1996). This contact-dependent reexpression is predominantly executed by the nasal RGCs and fewer temporal RGCs synthesize the protein. This is best explained by assuming that regenerating RGC axons and in particular nasal RGC axons require TAG-1 for intratectal growth and navigation to their retinotopic target sites.

\section{Suppression of TAG-1 Reexpression by Repeated Optic Nerve Transection}

Since lesion-induced onset of TAG-1 reexpression in RGCs correlates with the arrival of regenerating axons in the tectum, we determined the dependence of TAG-1 reexpression on target contact formation by interrupting the regenerating projection. Goldfish received bilateral optic nerve transections, were left to recover for 3 weeks, during which time TAG-1 reexpression reaches its maximum, and underwent a second, unilateral nerve transection. After 3 more days, both retinae were subjected to in situ hybridization for either TAG-1 or E587 mRNAs. Expression levels of E587 mRNA in RGCs were not affected by repeated optic nerve transection (Figs. 10a and 10b). In contrast, levels of TAG-1 mRNA markedly decreased in response to a second transection (Figs. 10c and 10d). This indicates that TAG-1 reexpression in RGCs might indeed be regulated by contact of retinal axons with the tectum and is downregulated when target contact is interrupted.

\section{Axon Regeneration in Vitro}

When segments of the goldfish retina, 14 days after lesion, are explanted on polylysine-coated coverslips, 

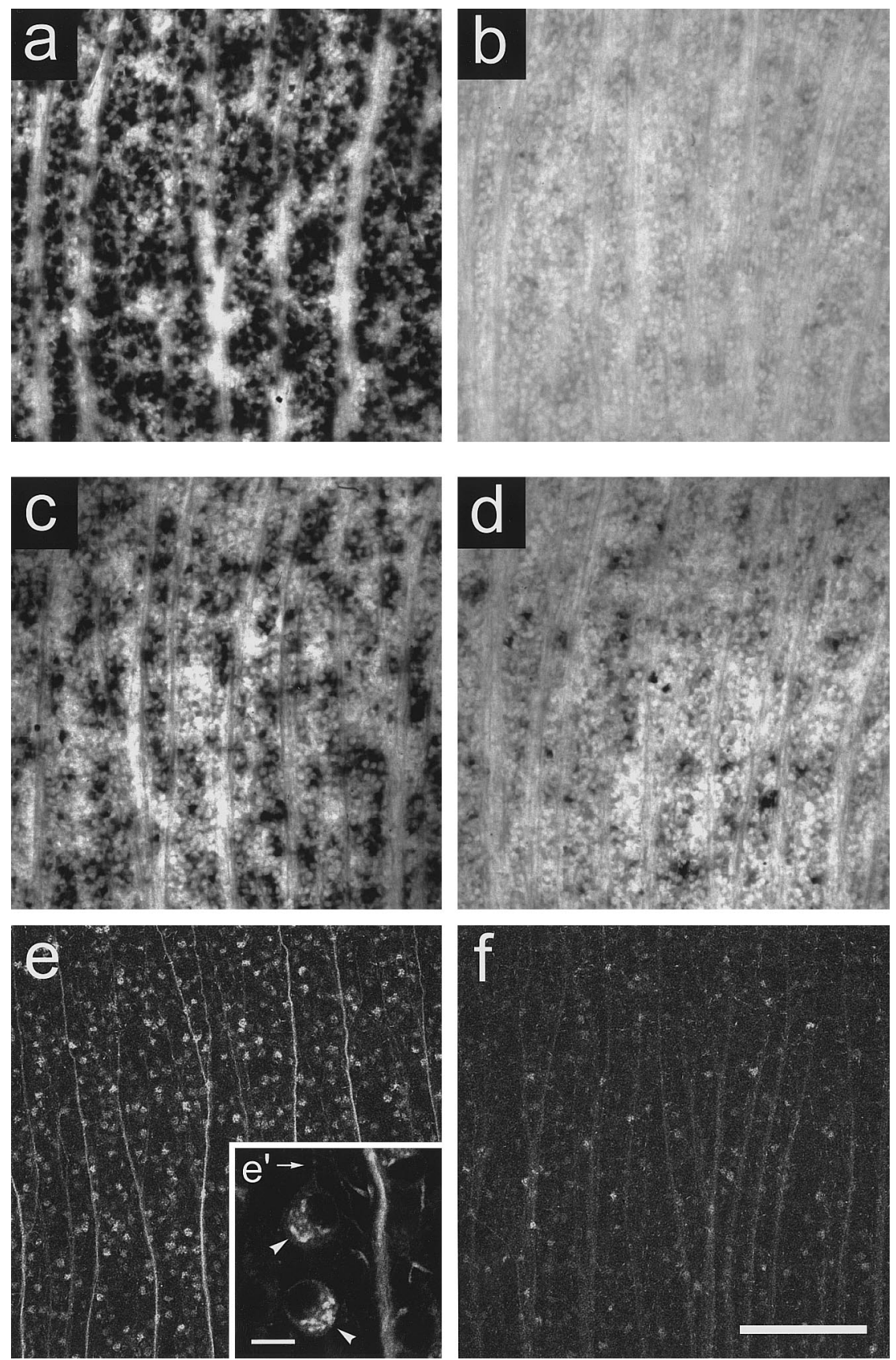

FIG. 8. TAG-1 reexpression in the retina following optic nerve transection. (a-f) Portions of retina wholemounts. (a, b) Retinae, 10 days after optic nerve lesion and subjected to in situ hybridizations, exhibit (a) E587 mRNA in almost all axotomized RGCs, whereas (b) TAG-1 mRNA is not yet detectable. (c, d) At 3 weeks after lesion, many RGCs reexpress TAG-1 mRNA, but the number of reexpressing RGCs is significantly greater in the nasal (c) than in the temporal (d) retina. (e, f) Retinae (3 weeks after lesion) exposed to anti-TAG-1 Abs exhibit labeling in many RGCs. TAG-1 does not appear on the surface of the axotomized RGCs but rather occurs in globular inclusions within the cytoplasm ( $\mathrm{e}^{\prime}$ arrowheads). The axons of TAG-1 reexpressing RGCs are unlabeled (e, f, arrow in $\mathrm{e}^{\prime}$ ). The RGC axons which are labeled in the nasal retina (e) are young growing axons from new RGCs at the margin. Young growing axons in the temporal retina (f) are at best weakly labeled, as are axons from axotomized RGCs. The number of TAG-1 reexpressing RGCs is significantly larger in the nasal (e) than in the temporal retina (f). Scale bar, $400 \mu \mathrm{m} ; \mathrm{e}^{\prime}, 10 \mu \mathrm{m}$. 

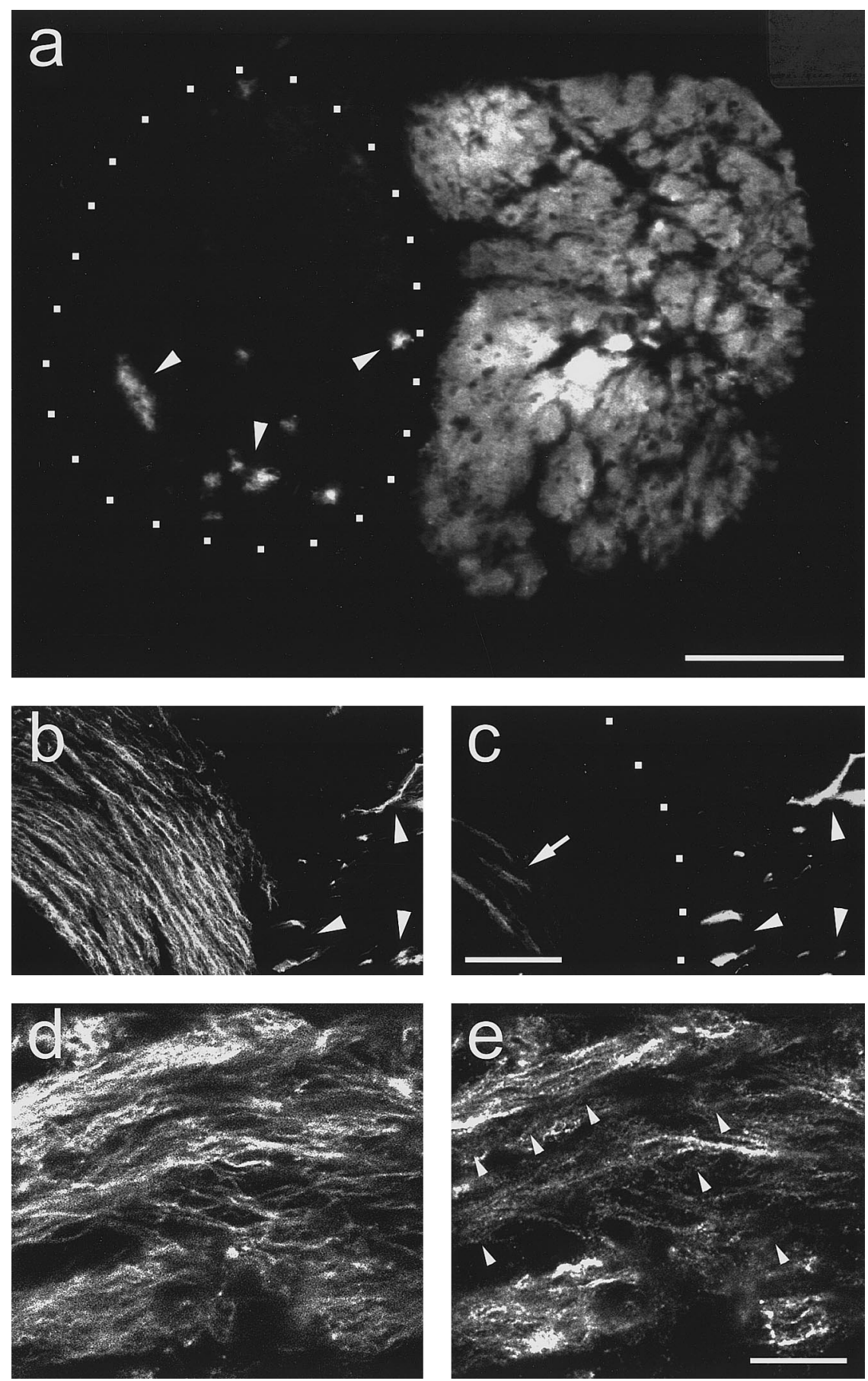

FIG. 9. TAG-1 reexpression on regenerating RGC axons in the optic nerve. (a) Cross-section through a normal, unlesioned nerve (left, surrounded by a dotted line) and its lesioned ( 3 weeks) counterpart. Anti-TAG-1 Abs label selectively the young (nasal) axons from new RGCs in the normal nerve (arrowheads), which form one or sometimes several small bundles. During regeneration, TAG-1-positive axons are found distributed throughout the optic nerve. (b, c) Oblique sections of the normal (right) and regenerating (left) optic nerves at 10 days after optic nerve lesion. (b) Anti-neurolin mAb labels all regenerating RGC axons and the bundles of young growing RGC axons (arrowheads) in the normal nerve. (c) Anti-TAG-1 Abs label a small subpopulation of neurolin positive axons in the regenerating nerve (arrow), which are likely to represent young growing rather than regenerating RGC axons. Most of the young neurolin positive young axons (arrowheads in b) in the normal nerve are also labeled by anti-TAG-1 (arrowheads in c). (d, e) Optic nerve wholemount at 3 weeks after lesion, showing TAG-1 labeled regenerating axons (e), which represent a subpopulation of those labeled by anti-neurolin mAb (d). Arrowheads (e) point to axonal profiles which are brightly labeled in (d). Scale bars: (a) $500 \mu \mathrm{m},(\mathrm{b}, \mathrm{c}) 200 \mu \mathrm{m},(\mathrm{d}, \mathrm{e}) 10 \mu \mathrm{m}$. 

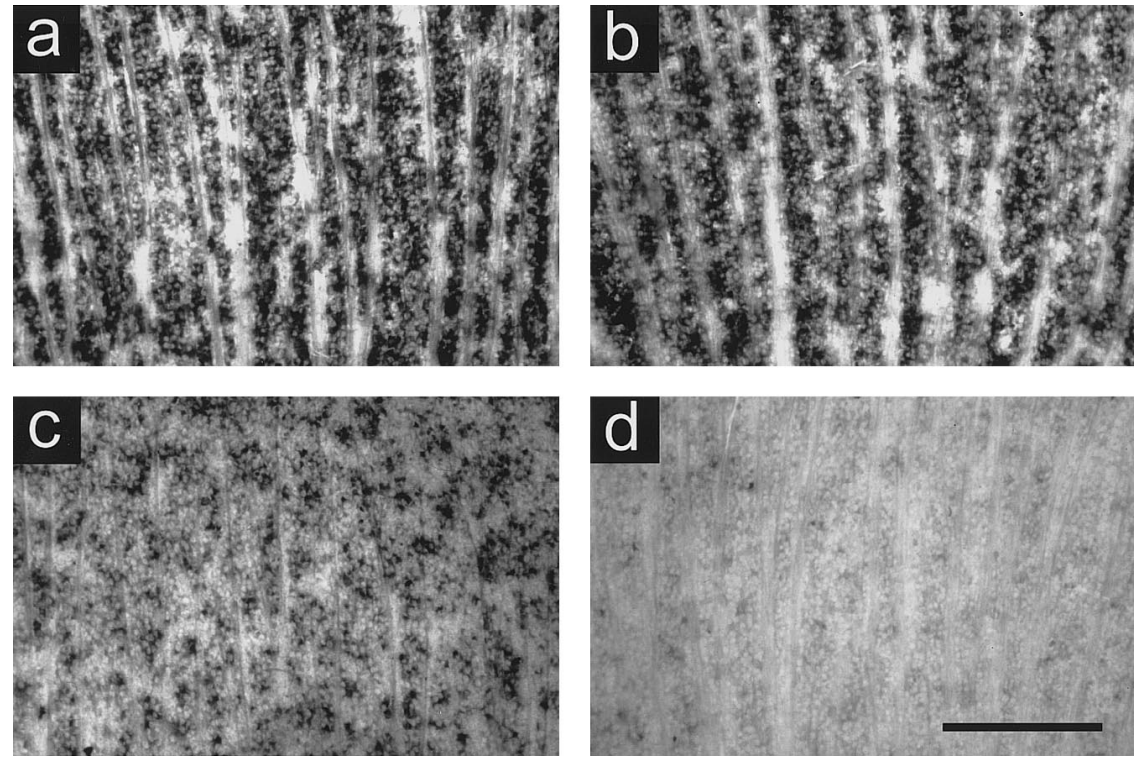

FIG. 10. Suppression of TAG-1 mRNA reexpression in axotomized RGCs. Wholemounts of retinae, 3 weeks after optic nerve transection (a, c) and 3 days after a second nerve transection (b, d). (a, b) In situ hybridizations show E587 mRNA in almost all RGCs at 3 weeks after ONS (a) and no change when the 3-week regenerating axons are sectioned again (b). (c, d) Many RGCs of the nasal retina reexpress TAG-1 mRNA 3 weeks after optic nerve lesion (c), but the in situ hybridization signals are markedly reduced in nasal RGCs after a second lesion. Scale bar, 400 $\mu \mathrm{m}$.

RGCs vigorously extend axons. These axons are TAG-1 immunoreactive (Fig. 11) regardless of whether they derive from the nasal or temporal retina. This indicates that the topographic restriction of TAG-1 reexpression is lost when retina segments are brought into culture and suggests that TAG-1 (re-) expression is regulated by intraretinal factors.

\section{DISCUSSION}

Analysis of TAG-1 in the fish visual pathway has revealed two novel features with regard to its expression. During development, TAG-1 is topographically restricted to nasal RGCs and nasal retinal axons throughout their path into the retinotopically appropriate caudal tectum. After optic nerve lesion in adult fish, TAG-1 is reexpressed-predominantly by nasal RGCs. The late onset of reexpression that occurs around 12 days after lesion correlates with the arrival of regenerating axons in the tectum (Stuermer and Easter, 1984a). The duration of TAG-1 reexpression corresponds to the time during which regenerating axons reestablish contacts throughout the tectum (Stuermer and Easter, 1984a; Stuermer, 1988b,c). Delayed onset and duration indicate a target dependency of TAG-1 reexpression, which is confirmed by finding a downregulation of TAG-1 upon interrupting the regenerating projection. The patterned expression of TAG-1 suggests that it may contribute to the topographic specification of RGCs and RGC axons and to their selective fasciculation but TAG-1 may also participate in the interaction of retinal axons with molecular cues in the tectum that guarantee the formation (and reestablishment) of the retinotopically organized projection.

TAG-1 expression during development. TAG-1/ axonin-1 occurs in all developing RGCs and RGC axons of warmblooded vertebrates (Wolfer et al., 1994; Halfter et al., 1994; Jung et al., 1997), but its restriction to nasal RGCs, as is here seen in fish, has not been observed. Nor has such a position-dependent expression pattern been found with the other IgSF proteins which were previously described in fish, NCAM, E587 antigen, and neurolin (Bastmeyer et al., 1990; Vielmetter et al., 1991; Paschke et al., 1992; Laessing and Stuermer, 1996). In contrast to TAG-1 the other IgSF CAMs are present in all developing RGCs. They play a role during growth cone elongation, fasciculation and navigation (Bastmeyer et al., 1995; Leppert et al., 1999). E587 antigen influences the mutual recognition of young axons in the nerve (Ott et al., 1998) and thus contributes to the development of the age-related axon order. In addition to 

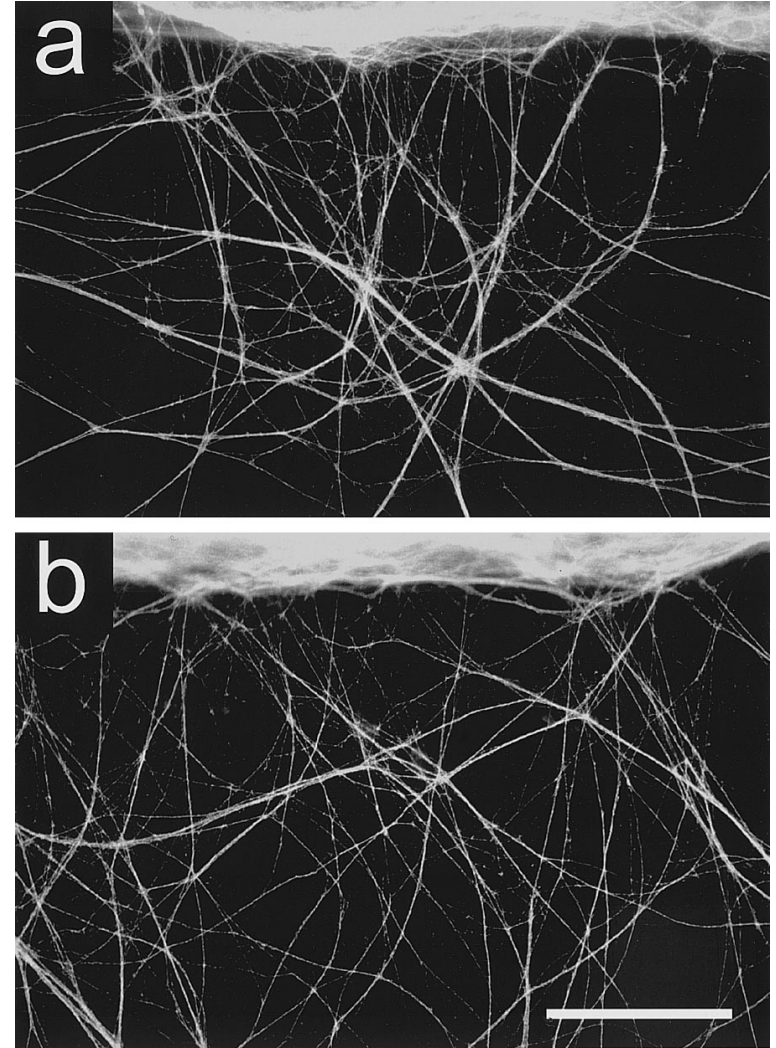

FIG. 11. Anti-TAG-1 Abs label regenerating RGC axons in vitro. Retinal explants, 14 days after optic nerve lesion, extend axons. These axons are labeled by anti-TAG-1 Abs regardless of whether they derive from nasal (a) or temporal (b) retinal explants. Scale bar, 100 $\mu \mathrm{m}$.

their order by age, retinal axons are organized by their origin from retinal sectors along their entire path (Scholes, 1979; Easter et al., 1981; Stuermer, 1988a) so that nasal axons are separate from temporal axons, and dorsal from ventral axons. The fact that TAG- 1 is found on the nasal axons from their origin to the tectum in the embryo and in young axons in adult fish suggests that TAG-1 might contribute to the selective fasciculation of young growing nasal axons. TAG-1 confers positiondependent identity and may control the developing spatial organization of nasal axons. To which extent such functions require homophilic and/or heterophilic interactions of TAG-1 with L1 (Rader et al., 1993; Kunz et al., 1998) or the L1-related E587 antigen (Giordano et al., 1997) or with other axonally expressed molecules remains to be examined.

TAG-1 not only occurs in its GPI-anchored form on the axonal surface but also exists as a soluble protein in the vitreous (Stoeckli et al., 1991) which apparently binds to intraretinal axons (as well as to cellular processes of unknown identity). It is conceivable that it affects axon growth and/or integrity of the tissue. Such may result from the complex interactions that TAG-1/ axonin-1 exhibits: e.g., with L1/NgCAM, NrCAM, neurocan, and phosphacan/protein-phosphatase $\beta$ (in Kunz et al., 1998). The cellular processes may possess TAG-1 binding proteins which differ from those present on the RGC axons because staining of the processes is and remains more intense than that of the temporal axons and than that of the nasal axons after PI-PLC treatment. The increase of TAG-1 in the vitreous following optic nerve transection may result from the increase of cells reexpressing and releasing TAG-1. Whether this increase is beneficial to the intraretinal axons or axotomized RGCs is not known. However, there is no reexpression in the axotomized visual system of mammals (Jung et al., 1997), where many RGCs die and where axons fail to spontaneously regenerate.

TAG-1 reexpression. In rodents, TAG-1 expression disappears from RGCs within 2 days after optic nerve lesion and is not reexpressed, even in the axons that regenerate in the presence of a sciatic nerve transplant (Jung et al., 1997). During regeneration in adult fish, axons neither reform age-related bundles-which correlates with the fact that all axons reexpress the IgSF CAM E587 antigen-nor do they segregate according to their origin from retinal sectors (Stuermer and Easter, 1984a; Stuermer, 1988b,c; Schmidt et al., 1988; Bastmeyer et al., 1990). If TAG-1 promotes recognition and fasciculation of nasal RGC axons during development, its delayed and target-dependent reexpression during regeneration could account for the disorder among the axons.

During axon regeneration, NCAM, E587 antigen and neurolin as well as the intracellular proteins Gap-43, reggie-1, and reggie-2 are upregulated by RGCs (for review: Stuermer and Leppert, 2000) within the first 4-6 days after optic nerve lesion. Whereas antineurolin and anti-E587 Abs detect the regenerating RGC axons (Paschke et al., 1992; Ankerhold et al., 1998; Ankerhold and Stuermer, 1999) as soon as they appear in the nerve (and prior to their arrival in the tectum), anti-TAG-1 Abs do not. This corresponds to the failure of the axotomized and axon-regenerating RGCs to reexpress TAG-1 mRNA prior to target contact. Moreover, TAG-1 reexpression is limited to certain portions of the axons, as it only shows up in the regenerating axons distal to the lesion site. The dynamics of protein transport and the emergence of axonin-1 on the surface of chick DRGs suggests that newly synthesized axonin-1 is exclusively inserted in the membrane of the growth cone (Vogt et 
al., 1996). Thereafter, as the growth cone elongates further, axonin-1, is also found on the axon behind the growth cone. Hence, it is possible that TAG-1 in regenerating fish RGCs is first brought to the growth cone as it navigates through the tectum, and later appears on the axons in the nerve and tract. This in turn implies that TAG-1 reexpression is induced by a retrograde signal from the growth cone.

The uneven and regulated expression pattern of TAG-1 in fish is consistent with the speculation that TAG-1-after induction by target contact-might be involved in axon-target interactions and in the retinotopic organization of the retinotectal pathway in fish where nasal axons terminate in the caudal tectum and temporal axons in the rostral tectum. This could mean that TAG-1 interacts with positional guidance cues in the tectum.

Such a role is rather unusual for an IgSF CAM but is consistent with new insights into the role of axonin-1 in the chick embryo, where axonin- 1 functions as a growth cone sensor or receptor for the interactions with floor plate-associated NrCAM (Stoeckli and Landmesser, 1998; Fitzli et al., 2000). Other IgSF CAMs can also function as receptors: DCC (deleted in colon rectal cancer) binds netrin-1 (Keino-Masu et al., 1996), ROBO binds proteins of the Slit family (Kidd et al., 1998) and neurolin in fish is involved in growth cone guidance by interaction with ligands as yet unidentified (Ott et al., 1998; Leppert et al., 1999; Stuermer and Bastmeyer, 2000). Molecules that are involved in guidance of RGC axons in the tectum are members of the ephrin/Eph receptor family, in particular ephrin A2, ephrin A5 and their cognate EphA receptors (Drescher et al., 1995, 1997; Monschau et al., 1997; Picker et al., 1999; Feldheim et al., 2000), as well as molecules of the RGM (Repulsive Guidance Molecule), family (Mueller et al., 1996; Mueller, 1999). Whether TAG-1 is involved in interactions, as for instance with RGM, remains to be shown.

An attractive speculation derives from the present observation that some RGCs of the temporal retina in addition to nasal RGCs reexpress TAG-1 during regeneration. It is known that many regenerating axons take abnormal routes and branch widely in the tectum before they reach and restrict their arbors to retinotopically appropriate sites (Stuermer, 1988b,c; Schmidt et al., 1988). It is conceivable that temporal RGCs erring into the caudal tectum are the ones that reexpress TAG-1 implying that contact with the caudal tectum is the relevant cue for TAG-1 upregulation. Such contacts are interrupted by a second lesion to the optic nerve which causes downregulation of TAG-1 reexpression in both nasal and temporal RGCs. Because regenerating RGC axons in vitro do not show the same nasal versus temporal difference in TAG-1 expression, experiments addressing the above speculation require in vivo assays. The observation that the restricted expression of TAG-1 by nasal RGCs is abolished by explanting retinal segments in culture in turn suggests that factors intrinsic to the retinotectal system control the topographically restricted expression of TAG-1. Expressional control may be exerted through cell contact-mediated signaling or through soluble factors in the vitreous. Soluble factors are, however, less likely to be responsible for TAG-1 reexpression after lesion for reasons discussed above. Moreover, putative factors are also needed for the regulation of intracellular versus membrane insertion of TAG-1 (Vogt et al., 1996), here evident during regeneration. These observations indicate that TAG-1 transcription is regulated in a position-dependent manner during RGC development in both the embryonic and adult retina and underlies further expressional control depending on the state and environment of the axon.

\section{EXPERIMENTAL METHODS}

\section{Animals}

Goldfish, zebrafish and zebrafish embryos were taken from breeding stocks in the animal research unit of the University of Konstanz. Fish were anesthetized in MS 222 (Sigma) prior to optic nerve transections according to established procedures and in compliance with animal welfare legislation. To study TAG-1 expression after repeated optic nerve transection, goldfish first received a bilateral optic nerve transection and were left to recover for 3 weeks. A second optic nerve transection was then performed on the right side. After 3 more days, both retinae were dissected and processed for wholemount in situ hybridization.

\section{Goldfish Retina Explants}

Retina explants were prepared following established protocols (Vielmetter and Stuermer, 1989) from fish which had received nerve transection $14 \mathrm{~d}$ prior to dissection. Isolated retinae were flat-mounted on Hybond $\mathrm{N}+$ membranes (Amersham), cut into $300 \mu \mathrm{m}$ wide segments on a Mcllwain tissue chopper and placed with the ganglion cell layer down, on polylysine-coated glass coverslips. Retinal explants were cultured in L-15 (Leibowitz) medium with 10\% fetal calf serum (FCS) and $0.4 \%$ methyl cellulose for $2 \mathrm{~d}$ at 22 
$27^{\circ} \mathrm{C}$ prior to fixation and immunohistochemical analysis.

\section{In Situ Hybridization}

Two different DIG-labeled antisense riboprobes and the appropriate sense controls were synthesized using a DIG labeling kit (Boehringer Mannheim) according to the manufacturer's instructions. Probes corresponded to positions 94-1188 (Ig-loops 1-4) and 94-1461 (Ig-loops 1-5) of a full length zebrafish TAG-1 cDNA clone (Warren et al., 1999). In situ hybridization was performed on wholemounts of goldfish and zebrafish retinae. Briefly, retinae were flat-mounted on Hybond $\mathrm{N}$ membranes (Amersham) and fixed in 4\% paraformaldehyde (PFA) in phosphate buffered saline (PBS) overnight at $4^{\circ} \mathrm{C}$. After washes in PBS $(3 \times 5 \mathrm{~min})$ at room temperature (RT), retinae were permeabilized in methanol $(2 \times 20$ $\mathrm{min},-20^{\circ} \mathrm{C}$ ). Following rehydration in $75 \%$ methanol/ 25\% PBS, 50\% methanol /50\% PBS, 25\% methanol/75\% PBS, and 100\% PBS (5 min each at RT), the retinae were incubated in PBST containing $10 \mu \mathrm{g} / \mathrm{ml}$ proteinase $\mathrm{K}$ (Boehringer Mannheim) for $10 \mathrm{~min}$ at RT. After 2 brief rinses in PBST, the retinae were postfixed in 4\% PFA (20 min, RT), washed thoroughly in PBST $(5 \times 5 \mathrm{~min}, \mathrm{RT})$ and prehybridized in hybridization $\operatorname{mix}(50 \%$ formamide, $5 \times$ SSC, $0.1 \%$ Tween-20, $1 \mathrm{mg} / \mathrm{ml} \mathrm{tRNA}$ (Boehringer Mannheim), $50 \mu \mathrm{g} / \mathrm{ml}$ Heparin (Sigma)) for at least $2 \mathrm{~h}$ at $55^{\circ} \mathrm{C}$. Hybridizations were performed overnight at $55^{\circ} \mathrm{C}$ with $100 \mathrm{ng} / \mathrm{ml}$ antisense or sense riboprobe in hybridization mix. Retinae were rinsed in 50\% formamide $/ 2 \times \operatorname{SSCT}\left(2 \times 30 \mathrm{~min}, 55^{\circ} \mathrm{C}\right)$, once in $2 \times$ SSCT $\left(15 \mathrm{~min}, 55^{\circ} \mathrm{C}\right)$, and twice in $0.2 \times$ SSCT (30 min each, $\left.55^{\circ} \mathrm{C}\right)$. For immunohistochemical detection of bound riboprobes, retinae were briefly rinsed in PBST, blocked in PBST containing 5\% bovine serum albumin (BSA, 2 h, RT) and incubated (overnight, $4^{\circ} \mathrm{C}$ ) with alkaline phosphatase-conjugated anti-DIG antibodies (Boehringer Mannheim), 1:5000 in blocking buffer. Labeling was visualized after extensive washes in PBST (at least $5 \times 15 \mathrm{~min}, \mathrm{RT}$ ) using the BM Purple substrate (Boehringer Mannheim). Finally, the wholemounts were rinsed in PBS and coverslipped in Mowiol. All sense controls were void.

For wholemount in situ hybridization of zebrafish embryos between 24 and 72 hours post fertilization (hpf), fish were staged, fixed and subjected to the above protocol. Following signal detection and washing in PBS, yolk sacs were removed and the embryos embedded in Mowiol.

\section{Expression and Purification of Recombinant TAG-1}

A cDNA sequence corresponding to positions 1-3024 of the full length zebrafish TAG-1 clone (Warren et al., 1999) was cloned into the expression vector pSecTagB (Invitrogen). CHO cells were transfected with this construct by calcium phosphate precipitation (Wigler et al., 1992) and selected using Zeozin (Invitrogen) according to the manufacturer's instructions. Stable transfectants were identified using antibodies specific for tetrahistidin (Qiagen) and the human myc-epitope (Calbiochem) attached to the recombinant protein, subcloned and expanded. For protein purification, $\mathrm{CHO}$ cells expressing soluble recombinant TAG-1 were grown in serumfree $\mathrm{CHO}$ medium with supplement (Biowhittaker), the supernatants harvested and recombinant TAG-1 purified over its polyhistidine tag using the Xpress protein purification system (Invitrogen).

\section{Production of Antibodies}

Purified recombinant TAG-1 protein (see Results, Figure 4) was used to immunize rabbits (chinchilla bastard) and Balb/c mice according to standard protocols. Hybridoma cells were produced under standard culture conditions, and supernatants were screened for TAG-1-specific staining in cryosections of goldfish and zebrafish brains as well as in Western blots of fish CNS tissue and recombinant TAG-1 (see Figure 4). For purification of IgG fractions, rabbit antisera were passed over a protein A column.

\section{PI-PLC-Treatment of Goldfish Retinae}

Flat-mounted live goldfish retinae were incubated in L-15 medium in the presence of $1 \mathrm{unit} / \mathrm{ml}$ of phosphatidylinositol-specific phospholipase C (PI-PLC; Boehringer Mannheim) for $1 \mathrm{~h}$ at $27^{\circ} \mathrm{C}$. The retinae were rinsed briefly with cold L-15 medium and immunostained live with antibodies to TAG-1 and E587 antigen (Bastmeyer et al., 1995). Control retinae were treated identically, but without PI-PLC.

\section{Immunohistochemistry}

Immunohistochemistry on cryosections was performed according to standard procedures. Briefly, 10 $\mu \mathrm{m}$ thick sections of fish CNS tissue were immersed in methanol $\left(5 \mathrm{~min} ;-20^{\circ} \mathrm{C}\right)$, washed 3 times in PBS (5 min each wash) and incubated with the relevant antibodies in blocking solution (PBS containing 1\% BSA and $0.02 \%$ thimerosal as a preservative) for $2 \mathrm{~h}$ at $37^{\circ} \mathrm{C}$. Following 
3 washes in PBS, sections were incubated with the appropriate secondary antibodies (donkey-anti-mouse or anti-rabbit-Cy-3 (Dianova) and goat-anti-mouse or anti-rabbit-ALEXA 488 (Molecular Probes; 1:1000 in blocking solution; $2 \mathrm{~h}$ at RT)). After 3 washes in PBS, sections were coverslipped in Mowiol containing npropylgallate as antifading agent. Wholemount preparations of retinae or retinal explant cultures were incubated with the relevant primary antibodies, diluted in L-15 medium containing 10\% FCS, either live for $1 \mathrm{~h}$ at RT or after permeabilization in methanol (10 min, $-20^{\circ} \mathrm{C}$ ) overnight at $4^{\circ} \mathrm{C}$, and thereafter treated as described above. For wholemount immunostaining, zebrafish embryos, between 24 and $72 \mathrm{hpf}$, were fixed in $4 \%$ PFA in PBS (10 min, RT), permeabilized in methanol $\left(3 \mathrm{~min},-20^{\circ} \mathrm{C}\right)$, washed in PBS $(5 \times 5 \mathrm{~min}, \mathrm{RT})$. Nonspecific antibody binding was reduced by incubation in blocking solution (PBS containing 1\% BSA and 1\% DMSO (dimethylsulfoxide); 1 h, RT). Embryos were exposed to the relevant primary antibodies diluted in blocking solution overnight at $4^{\circ} \mathrm{C}$. After extensive washing $(5 \times 5 \mathrm{~min})$ in PBS, fluorochrome-conjugated secondary antibodies were applied in blocking solution $(2 \mathrm{~h}, \mathrm{RT})$. The embryos were washed again $(5 \times 5 \mathrm{~min}$ in PBS) and, after removal of yolk sacs, embedded in Mowiol. To immunolabel goldfish optic nerves and tecta as wholemount preparations, the same protocol was applied.

Primary antibodies used were mAbs anti-E587-antigen (Vielmetter et al., 1991), anti-neurolin (Leppert et al., 1999) and anti-zebrafish TAG-1 (clones T744 and T819) as well as purified rabbit-anti-zebrafish TAG-1 IgG.

\section{Gel Electrophoresis and Immunoblotting}

For SDS-PAGE and immunoblots (Sambrook et al., 1989), proteins were separated on 7.5 or $10 \%$ minigels under reducing or non-reducing conditions. Following gel electrophoresis, proteins were transferred to Hybond-C Super nitrocellulose membranes (Amersham Buchler) in a tank blot apparatus. The membranes were air dried, blocked in PBS containing 0.05\% Tween-20 and 3\% non-fat dried milk (1 h, RT) and incubated with the relevant antibodies in blocking solution for $2 \mathrm{~h}$ at RT or overnight at $4^{\circ} \mathrm{C}$. Following 4 washes in PBS/0.05\% Tween 20, the blots were incubated with HRP-conjugated goat-anti-rabbit or goat-anti-mouse antibodies in blocking solution for $2 \mathrm{~h}$ at RT, and, after extensive washing, developed using the enhanced chemoluminescence (ECL) substrate SuperSignal (Pierce) and ECL hyperfilm (Amersham Buchler).

\section{ACKNOWLEDGMENTS}

This work was supported by a grant from the EC (BMH4-CT972653), the DFG, and the Fonds der Chemischen Industrie (FCI) to C.A.O.S. and by a grant of the NIH to J.T.W.

\section{REFERENCES}

Ankerhold, R., Leppert, C. A., Bastmeyer, M., and Stuermer, C. A. O. (1998). E587 antigen is upregulated by goldfish oligodendrocytes after optic nerve lesion and supports retinal axon regeneration. Glia 23: 257-270.

Ankerhold, R., and Stuermer, C. A. O. (1999). Fate of oligodendrocytes during retinal axon degeneration and regeneration in the goldfish visual pathway. J. Neurobiol. 41: 572-584.

Bastmeyer, M., Leppert, C. A., Ott, H., and Stuermer, C. A. O. (1995). Fish E587 glycoprotein, a member of the L1 family of cell adhesion molecules, participates in axonal fasciculation and the age-related order of ganglion cell axons in the goldfish retina. J. Cell Biol. 130: 969-976.

Bastmeyer, M., Schlosshauer, B., and Stuermer, C. A. O. (1990). The spatiotemporal distribution of N-CAM in the retinotectal pathway of adult goldfish detected by the monoclonal antibody D3. Development 108: 299-311.

Brümmendorf, T., and Rathjen, F. (1995). Cell Adhesion Molecules I: Immunoglobulin Superfamily. Academic Press, London.

Burns, F. R., Von Kannen, S., Guy, L., Raper, J. A., Kamholz, J., and Chang, S. (1991). DM-GRASP, a novel immunoglobulin superfamily axonal surface protein that supports neurite extension. Neuron 7 : 209-220.

Drescher, U., Bonhoeffer, F., and Müller, B. K. (1997). The Eph family in retinal axon guidance. Curr. Opin. Neurobiol. 7: 75-80.

Drescher, U., Kremoser, C., Handwerker, C., Loschinger, J., Noda, M., and Bonhoeffer, F. (1995). In vitro guidance of retinal ganglion cell axons by RAGS, a 25-kDa tectal protein related to ligands for Eph receptor tyrosine kinases. Cell 82: 359-370.

Easter, S. S., Jr., Rusoff, A. C., and Kish, P. E. (1981). The growth and organization of the optic nerve and tract in juvenile and adult goldfish. J. Neurosci. 1: 793-811.

Easter, S. S., Jr., and Stuermer, C. A. O. (1984). An evaluation of the hypothesis of shifting terminals in goldfish optic tectum. J. Neurosci. 4: $1052-1063$.

Feldheim, D. A., Kim, Y.-I., Bergemann, A. D., Frisén, J., Barbacid, M., and Flanagan, J. G. (2000). Genetic analysis of ephrin-A2 and ephrin-A5 shows their requirement in multiple aspects of retinocollicular mapping. Neuron 25: 563-574.

Felsenfeld, D. P., Hynes, M. A., Skoler, K. M., Furley, A. J., and Jessell, T. M. (1994). TAG-1 can mediate homophilic binding, but neurite outgrowth on TAG-1 requires an L1-like molecule and $\beta 1$ integrins. Neuron 12: 675-690.

Fitzli, D., Stoeckli, E. T., Kunz, S., Siribour, K., Rader, C., Kunz, B., Kozlov, S. V., Buchstaller, A., Lane, R. P., Suter, D. M., Dreyer, W., and Sonderegger, P. (2000). A direct interaction of axonin-1 with $\mathrm{NgCAM}$-related cell adhesion molecule (NrCAM) results in guidance, but not growth of commissural axons. J. Cell Biol. 149: 951968.

Furley, A. J., Morton, S. B., Manalo, D., Karagogeos, D., Dodd, J., and Jessell, T. M. (1990). The axonal glycoprotein TAG-1 is an immu- 
noglobulin superfamily member with neurite outgrowth-promoting activity. Cell 61: 157-170.

Giordano, S., Laessing, U., Ankerhold, R., Lottspeich, F., and Stuermer, C. A. O. (1997). Molecular characterization of E587 antigen: An axonal recognition molecule expressed in the goldfish central nervous system. J. Comp. Neurol. 377: 286-297.

Halfter, W., Yip, Y. P. L., and Yip, J. W. (1994). Axonin-1 is expressed primarily in subclasses of avian sensory neurons during outgrowth. Dev. Brain Res. 78: 87-101.

Johns, P. A. (1977). Growth of the adult goldfish eye. III: Source of the new retinal cells. J. Comp. Neurol. 176: 343-357.

Jung, M., Petrausch, B., and Stuermer, C. A. O. (1997). Axon-regenerating retinal ganglion cells in adult rats synthesize the cell adhesion molecule L1 but not TAG-1 or SC-1. Mol. Cell. Neurosci. 9: 116-131.

Keino-Masu, K., Masu, M., Hinck, L., Leonardo, E. D., Chan, S. S. Y., Culotti, J. G., and Tessier-Lavigne, M. (1996). Deleted in Colorectal Cancer (DCC) encodes a netrin receptor. Cell 87: 175-185.

Kidd, T., Brose, K., Mitchell, K. J., Fetter, R. D., Tessier-Lavigne, M., Goodman, C. S., and Tear, G. (1998). Roundabout controls axon crossing of the CNS midline and defines a novel subfamily of evolutionarily conserved guidance receptors. Cell 92: 205-215.

Kuhn, T. B., Stoeckli, E. T., Condrau, F. G., Rathjen, F. G., and Sonderegger, P. (1991). Neurite outgrowth on immobilized axonin-1 is mediated by heterophilic interaction with L1 (G4). J. Cell Biol. 115: 1113-1126.

Kunz, S., Spirig, M., Ginsburg, C., Buchstaller, A., Berger, P., Lanz, R., Rader, C., Vogt, L., Kunz, B., and Sonderegger, P. (1998). Neurite fasciculation mediated by complexes of axonin-1 and $\mathrm{Ng}$ cell adhesion molecule. J. Cell Biol. 143: 1673-1690.

Laessing, U., and Stuermer, C. A. O. (1996). Spatiotemporal pattern of retinal ganglion cell differentiation revealed by the expression of neurolin in embryonic zebrafish. J. Neurobiol. 29: 65-74.

Leppert, C. A., Diekmann, H., Paul, C., Laessing, U., Marx, M., Bastmeyer, M., and Stuermer, C. A. O. (1999). Neurolin Ig domain 2 participates in retinal axon guidance and Ig domains 1 and 3 in fasciculation. J. Cell Biol. 144: 339-349.

Monschau, B., Kremoser, C., Ohta, K., Tanaka, H., Kaneko, T., Yamada, T., Handwerker, C., Hornberger, M. R., Löschinger, J., Pasquale, E. B., Siever, D. A., Verderame, M. F., Müller, B. K., Bonhoeffer, F., and Drescher, U. (1997). Shared and distinct functions of RAGS and ELF-1 in guiding retinal axons. EMBO J. 16: 1258-1267.

Müller, B. K. (1999). Growth cone guidance: First steps towards a deeper understanding. Annu. Rev. Neurosci. 22: 351-388.

Müller, K., Jay, D., and Bonhoeffer, F. (1996). Chromophore-assisted laser inactivation of a repulsive axonal guidance molecule. Curr. Biol. 6: 1497-1502.

Ott, H., Bastmeyer, M., and Stuermer, C. A. O. (1998). Neurolin, the goldfish homolog of DM-GRASP, is involved in retinal axon pathfinding to the optic disk. J. Neurosci. 18: 3363-3372.

Paschke, K. A., Lottspeich, F., and Stuermer, C. A. O. (1992). Neurolin, a cell surface glycoprotein on growing retinal axons in the goldfish visual system, is reexpressed during retinal axonal regeneration. J. Cell Biol. 117: 863-875.

Picker, A., Brennan, C., Reifers, F., Clarke, J., Holder, N., and Brand, M. (1999). Requirement for the zebrafish mid-hindbrain boundary in midbrain polarisation, mapping and confinement of the retinotectal projection. Development 126: 2967-2978.

Pourquié, O., Corbel, C., Le Caer, J.-P., Rossier, J., and Le Douarin, N. M. (1992). BEN, a surface glycoprotein of the immunoglobulin superfamily, is expressed in a variety of developing systems. Proc. Natl. Acad. Sci. USA 89: 5261-5265.

Rader, C., Stoeckli, E. T., Ziegler, U., Osterwalder, T., Kunz, B., and Sonderegger, P. (1993). Cell-cell adhesion by homophilic interaction of the neural cell recognition molecule axonin-1. Eur. J. Biochem. 215: 133-141.

Sambrook, J., Fritsch, E. F., and Maniatis, T. (1989). Molecular Cloning: A Laboratory Manual. Cold Spring Harbor Laboratory Press, Cold Spring Harbor, New York.

Schmidt, J. T., Turcotte, J. C., Buzzard, M., and Tieman, D. G. (1988). Staining of regenerated optic arbors in goldfish tectum: Progressive changes in immature arbors and a comparison of mature regenerated arbors with normal arbors. J. Comp. Neurol. 269: 565-591.

Scholes, J. (1979). Nerve fibre topography in the retinal projection to the tectum. Nature 278: 620-624.

Stoeckli, E. T., Kuhn, T. B., Duc, C. O., Ruegg, M. A., and Sonderegger, P. (1991). The axonally secreted protein axonin-1 is a potent substratum for neurite growth. J. Cell Biol. 112: 449-455.

Stoeckli, E. T., and Landmesser, L. T. (1995). Axonin-1, Nr-CAM, and $\mathrm{Ng}$-CAM play different roles in the in vivo guidance of chick commissural neurons. Neuron 14: 1165-1179.

Stoeckli, E. T., Sonderegger, P., Pollerberg, E. G., and Landmesser, L. T. (1997). Interference with axonin-1 and NrCAM interactions unmasks a floor-plate activity inhibitory for commissural axons. Neuron 18: 209-221.

Stoeckli, E. T., and Landmesser, L. (1998). Axon guidance at choice points. Curr. Opin. Neurobiol. 8: 73-79.

Stuermer, C. A. O., and Easter, S. S., Jr. (1984a). A comparison of the normal and regenerated retinotectal pathways of goldfish. J. Comp. Neurol. 223: 57-76.

Stuermer, C. A. O., and Easter, S. S., Jr. (1984b). Rules of order in the retinotectal fascicles of goldfish. J. Neurosci. 4: 1045-1051.

Stuermer, C. A. O. (1984). Rules for retinotectal terminal arborizations in the goldfish optic tectum: A whole-mount study. J. Comp. Neur. 229: 214-232.

Stuermer, C. A. O. (1988a). Retinotopic organization of the developing retinotectal projection in the zebrafish embryo. J. Neurosci. 8: 45134530.

Stuermer, C. A. O. (1988b). Trajectories of regenerating retinal axons in the goldfish tectum: I. A comparison of normal and regenerated axons at late regeneration stages. J. Comp. Neurol. 267: 55-68.

Stuermer, C. A. O. (1988c). Trajectories of regenerating retinal axons in the goldfish tectum: II. Exploratory branches and growth cones on axons at early regeneration stages. J. Comp. Neurol. 267: 69-91.

Stuermer, C. A. O., and Leppert, C. A. (2000). Molecular determinants of retinal axon pathfinding in fish. In Nerve Regeneration (N. Ingoglia and M. Murray, Eds.), Marcel Dekker, New York.

Stuermer, C. A. O., and Bastmeyer, M. (2000). The retinal axon's pathfinding to the optic disk. Progr. in Neurobiol. 62: 197-214.

Tanaka, H., Matsui, T., Agata, A., Tomura, M., Kubota, I., McFarland, K. C., Kohr, B., Lee, A., Phillips, H. S., and Shelton, D. L. (1991). Molecular cloning and expression of a novel adhesion molecule, SC1. Neuron 7: 535-545.

Vielmetter, J., Lottspeich, F., and Stuermer, C. A. O. (1991). The monoclonal antibody E587 recognizes growing (new and regenerating) retinal axons in the goldfish retinotectal pathway. J. Neurosci. 11: 3581-3593.

Vogt, L., Giger, R. J., Ziegler, U., Kunz, B., Buchstaller, A., Hermens, W. T. J. M. C., Kaplitt, M. G., Rosenfeld, M. R., Pfaff, D. W., Verhaagen, J., and Sonderegger, P. (1996). Continuous renewal of the axonal pathway sensor apparatus by insertion of new sensor molecules into the growth cone membrane. Curr. Biol. 6: 1153-1158. 
Warren, J. T., Chandrasekhar, A., Kanki, J. P., Rangarajan, R., Furley, A. J., and Kuwada, J. Y. (1999). Molecular cloning and developmental expression of a zebrafish axonal glycoprotein similar to TAG-1. Mech. Dev. 80: 197-201.

Wigler, M., Sweet, R., Sim, G. K., Wold, B., Pellicer, A., Lacy, E., Maniatis, T., Silverstein, S., and Axel, R. (1992). Transformation of mammalian cells with genes from prokaryotes and eukaryotes. Biotechnology 24: 444-452.

Wolfer, D. P., Giger, R. J., Stagliar, M., Sonderegger, P., and Lipp, H. P. (1998). Expression of the axon growth-related neural adhesion molecule TAG-1/axonin-1 in the adult mouse brain. Anat. Embryol. (Berl) 197: 177-185.

Received September 4, 2000

Revised October 22, 2000

Accepted November 6, 2000

Published online J anuary 16, 2001 